\title{
EL DESARROLLO TURÍSTICO EN LAS ISLAS VERDES DE CANARIAS: EL CASO DE LA ISLA DE LA PALMA (2000-2019)
}

\author{
Carlos S. Martín Fernández* \\ Universidad de La Laguna \\ https://orcid.org/0000-0002-3400-0960
}

\section{RESUMEN}

La isla de La Palma (Canarias), una de las denominadas como Islas Verdes, ha mantenido históricamente una apuesta por un modelo económico basado en la actividad agraria de exportación. En las últimas décadas, ante la amenazante desaparición de la protección institucional a su principal cultivo (el plátano), ha variado su estrategia activando la actividad inmobiliario-turística como estrategia de desarrollo. Un cambio que acontece en una coyuntura poco oportuna, al coincidir con un marco institucional regional que controlaba el incremento de la oferta turística. El relato de las contradicciones institucionales acaecidas constituye el objeto de este artículo.

Palabras clave: Desarrollo inmobiliario-turístico; normativa; Islas Canarias; Islas Verdes; La Palma.

\section{Tourism development in the green islands of the Canary Islands (Spain): the case of the island of La Palma (2000-2019)}

\begin{abstract}
The island of La Palma (Canary Islands), one of those called Islas Verdes, was historically maintained an economic model based on agricultural export activity. In recent decades, in the face of the threatening disappearance of institutional protection to its main crop (the banana), it has varied its strategy by activating real estate-tourism activity as a development strategy. A change that is at a timely juncture, in the same way as it coincided with a regional
\end{abstract}

Fecha de recepción:12 de noviembre de 2019

Fecha de aceptación: 10 de junio de 2020

* Departamento de Geografía e Historia. Universidad de La Laguna. C/ Prof. José Luis Moreno Becerra, s/n. Facultad de Humanidades. 38200 San Cristóbal de La Laguna. SANTA CRUZ DE TENERIFE (España). E-mail: csmartin@ull.es 
institutional framework that controlled the increase in the tourist offer. The story of the institutional contradictions that occurred is the subject of this article.

Keywords: Real estate-tourism development; regulations; Canary Islands: Green Islands, La Palma.

\section{INTRODUCCIÓN: LA ESTRATEGIA DE DESARROLLO ECONÓMICO DE LA ISLA DE LA PALMA}

En Canarias conocemos como Islas Verdes a las más occidentales: La Palma, La Gomera y El Hierro. En éstas, el sector primario ha ocupado históricamente un lugar central en su estructura económica, en clara diferencia con el resto de las islas del Archipiélago en las que el peso de los subsectores turismo y construcción suponen la centralidad de sus respectivos PIB.

De entre estas Islas Verdes destaca, por su magnitud económica y territorial la isla de La Palma ${ }^{1}$. En ésta, la actividad agrícola ha sido el pilar básico sobre el que históricamente se ha asentado su economía. Una agricultura muy apegada socialmente, que ha desempeñado múltiples funciones (paisajísticas, ecológicas y económicas) y que presenta dos modelos diferentes, aunque complementarios. De una parte, la agricultura que se produce en las "medianías" (entre los 600 y $1.000 \mathrm{~m}$ ), mayoritariamente para autoconsumo y mercado interior, en situación de retroceso. Y de otra, la agricultura de exportación en la costa, con un cultivo casi hegemónico, el plátano ${ }^{2}$, que pervive auxiliado por las rentas institucionales (ayudas comunitarias), siendo el principal dinamizador económico insular junto a los ingresos derivados del sector público (parados, pensionistas y funcionarios).

Este modelo híbrido de servicios y producción platanera ha sido hasta períodos recientes competitivo en términos económicos. En la isla de La Palma, las expectativas de desarrollo turístico se han mantenido en un segundo plano por las notables deficiencias en los transportes aéreos ${ }^{3}$. Porque los suelos con mayores posibilidades de uso turístico coinciden

1 Es la isla más noroccidental del Archipiélago Canario. Pertenece a la provincia de Santa Cruz de Tenerife y cuenta con una superficie de 708,32 km2. Su población es de 81.863 habitantes, presentando una evolución reciente caracterizada por la pérdida de población. En lo que va del s. XXI el dato más alto se registró en 2010, donde se contabilizaron 87.324 habitantes, un siglo que arrancó con 82.483. Una población muy envejecida, los grupos de edad hasta los 39 años decrecen en población, mientras que de 40 en adelante aumentan, a excepción de tres grupos: 60 a 64, 70 a 74, y 75 a 79. Sin embargo, el grupo que más se incrementa en la isla en términos relativos es el de las personas con 100 o más años, mientras que el grupo que más decrece es el de 25 a 29 años (Instituto Canario de Estadística, Gobierno de Canarias, 2018). De gran valor natural y paisajístico, el $35 \%$ de su superficie es espacio protegido conforme a distintas figuras, destacando el Parque Nacional de la Caldera de Taburiente (uno de los cuatro existentes en el Archipiélago). Desde el año 2002 la totalidad de la Isla es Reserva Mundial de la Biosfera conforme al Programa MaB de la Unesco.

2 En La Palma el plátano ocupa el 41,1 \% de su superficie cultivada (ISTAC-Gobierno de Canarias, 2018) y aporta el $36,7 \%$ de la producción total de plátanos de Canarias, siendo la segunda isla productora del Archipiélago con 143.592 Tm (Asociación de productores de plátanos de Canarias-ASPROCAN, 2018).

3 Hasta 1970 la isla contaba con un aeródromo de pista corta comprometida geográficamente para los vuelos regulares. Este año se inaugura un nuevo aeropuerto en Mazo-Breña Baja, que se irá ampliado en años posteriores, habilitándose para atender el tráfico diario con las islas y semanal con la península y Europa. 
con los de mayor productividad platanera, encareciendo las operaciones de compraventa y su posterior reconversión a usos turísticos ${ }^{4}$. Y porque una atomizada y conservadora pequeña propiedad ha mostrado escaso interés hacia la función turística, concentrando sus inversiones en una rentable economía platanera. De esta forma, apoyada en los beneficios agrícolas y las ayudas institucionales, la isla de La Palma ha evitado centrar su crecimiento en el binomio construcción-servicios, y con una limitada e incipiente actividad turística se distingue de las islas de mayor tradición y peso turístico, las también denominadas Islas Turísticas: Tenerife, Gran Canaria, Fuerteventura y Lanzarote (Hernández, González y Parreño, 2016; Hernández,2009).

No obstante, sin llegar a ser un sector económico hegemónico, en la Isla se ha asentado una peculiar modalidad turística basada en la valorización de su patrimonio natural y cultural $^{5}$, a través de modelos tipo turismo rural, ecoturismo y agroturismo (Olmos, 1998; Hernández, 2006; López, 2007; Fernández, 2010; González, Hernández y Parreño, 2016; Morales, 2017), implantado de diferente forma en todos sus municipios y con sólo dos modestos núcleos turísticos hoteleros y sobre todo extra hoteleros orientados al segmento sol y playa: Los Cancajos (Breña Baja) y Puerto Naos (Los Llanos de Aridane), que junto a un gran resort aislado en Fuencaliente, conforma una oferta total de 14.233 plazas turísticas (Promotur). Con estas características, bajo la etiqueta "Isla Bonita", La Palma se ha concentrado en una demanda turística interesada fundamentalmente en recursos naturales (bosques, volcanes, calderas) y culturales (inmuebles de valor patrimonial, senderismo, gastronomía), configurándose como un modelo de producción turística alternativa al sol y playa general del Archipiélago.

Tabla 1

EVOLUCIÓN DE LAS PLAZAS ALOJATIVAS EN LA ISLA DE LA PALMA (2003-2018)

\begin{tabular}{|c|c|c|c|c|c|c|c|c|c|c|c|c|}
\hline & \multicolumn{2}{|c|}{2003} & \multicolumn{2}{|c|}{2006} & \multicolumn{2}{c|}{2009} & \multicolumn{2}{|c|}{2012} & \multicolumn{2}{c|}{2015} & \multicolumn{2}{c|}{2018} \\
\cline { 2 - 12 } & Plazas & $\begin{array}{c}\text { Peso en } \\
\text { Canarias }\end{array}$ & Plazas & $\begin{array}{c}\text { Peso en } \\
\text { Canarias }\end{array}$ & Plazas & $\begin{array}{c}\text { Peso en } \\
\text { Canarias }\end{array}$ & Plazas & $\begin{array}{c}\text { Peso en } \\
\text { Canarias }\end{array}$ & Plazas & $\begin{array}{c}\text { Peso en } \\
\text { Canarias }\end{array}$ & Plazas & $\begin{array}{c}\text { Peso en } \\
\text { Canarias }\end{array}$ \\
\hline Hotelera & 1.937 & 1,3 & 3.757 & 2,1 & 3.831 & 1,9 & 3.895 & 1,8 & 3.876 & 1,8 & 3.882 & 1,8 \\
\hline Extrahotelera & 6.353 & 2,7 & 6.800 & 3,0 & 7.073 & 3,2 & 7.100 & 3,3 & 7.152 & 3,4 & 10.351 & 4,3 \\
\hline
\end{tabular}

Fuente: Promotur Turismo de Canarias, Gobierno de Canarias.

4 "El precio del suelo de las fincas de plátano ha subido enormemente desde 1993 hasta la actualidad [se refiere a 1999], casi duplicándose su cifra, pagándose hoy en día cerca de $6.000 \mathrm{ptas} . / \mathrm{m} 2$ de suelo bruto. Si añadimos los costes de urbanización de un Plan Parcial, obtenemos que la posibilidad de poner en marcha estas zonas como áreas turísticas resulta muy difícil” (Daranas, 1999:25).

5 El 43 \% de las inversiones entre 1992-2005 de la Asociación para el Desarrollo Rural de la Isla de La Palma (ADER - La Palma), organismo dedicado a dinamizar e impulsar la "medianía insular", se centraron en dicha modalidad: rehabilitación de casas rurales y promoción del turismo rural en el exterior. Una actividad que se entrelaza con otras igualmente dinamizadoras del paisaje y la cultura rural claramente imbricadas en la oferta turística: rehabilitación de patrimonio, centros de interpretación, etc. 
Tabla 2

LLEGADA DE TURISTAS A LA ISLA DE LA PALMA

(2010-2018)

\begin{tabular}{|c|c|c|c|c|c|c|c|c|}
\hline 2010 & 2011 & 2012 & 2013 & 2014 & 2015 & 2016 & 2017 & 2018 \\
\hline 150.981 & 167.278 & 167.707 & 150.486 & 161.992 & 188.332 & 238.321 & 293.900 & 274.404 \\
\hline
\end{tabular}

Fuente: Promotur Turismo de Canarias, Gobierno de Canarias.

En las últimas décadas esta estrategia de desarrollo ha entrado en cuestión. El escenario económico de desprotección del sector primario, la amenazante reducción o eliminación de las ayudas al cultivo del plátano y al desarrollo endógeno, han puesto en primer plano el debate en torno a la necesidad de incorporar estilos semejantes a los de las islas turísticas. Una controversia que definitivamente ha madurado en un contexto regional poco favorable al desarrollo turístico, al coincidir con una coyuntura (finales de la década de los 90) de crecimiento cuantitativo de la oferta de plazas y de disminución sustancial de los beneficios, por desajuste entre una sobreoferta alojativa y una demanda turística en declive $^{6}$. La solución de la administración autonómica canaria en pro de ajustar el sector interviniendo en el crecimiento del suelo a ocupar por los alojamientos y equipamientos turísticos, cortó las aspiraciones de incorporación de La Palma al modelo general del Archipiélago y obligó a sus principales instituciones políticas y económicas a luchar contra corriente en la búsqueda de un ansiado cambio de modelo.

El presente artículo tiene por objetivo describir este azaroso proceso de incorporación de la mayor isla no turística de masas de Canarias a esta modalidad. Un asunto complejo e inacabado, que en este trabajo se aborda en relación con el contexto socioeconómico insular, vinculándolo a las posturas de los diferentes actores y colectivos interesados. Se trata de un trabajo fundamentalmente cualitativo, en el que se aborda el papel del marco institucional en los procesos de desarrollo, en tanto que gestores de unas determinadas y conflictivas "reglas de juego", que para el caso que nos ocupa, han sido fundamentales en la política turística insular.

\footnotetext{
6 El profesor Simancas, en su documentada síntesis sobre el Tercer Boom Turístico de Canarias, indica en relación con las expectativas y utilizando distintas fuentes y contenidos, cuatro escenarios con guarismos que van desde las 353.435 a las 1.332.878 plazas (Simancas, 2019:477).
} 
Figura 1

MAPA DE LOCALIZACIÓN

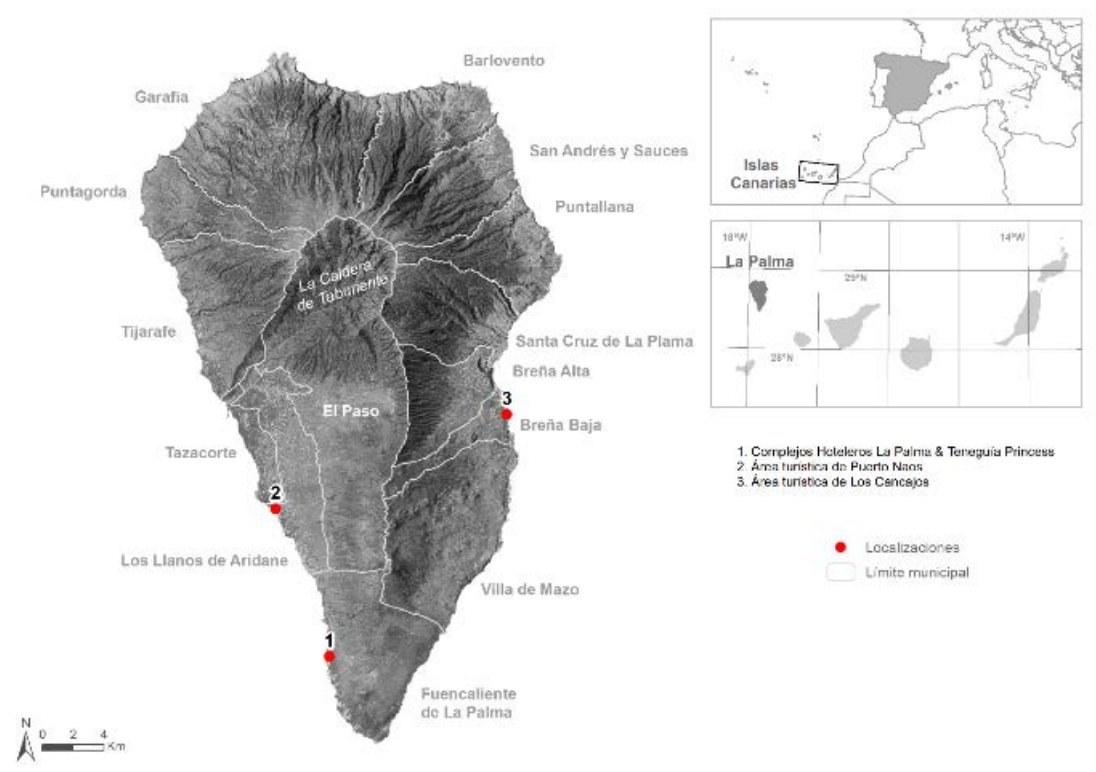

Fuente: Grafcan, Elaboración García Cruz, J.I

\section{LA PALMA EN EL CONTEXTO DEL TERCER BOOM TURÍSTICO DE CANARIAS}

La Palma, quedó fuera del denominado Primer Boom Turístico (1969-1975) y no será hasta mediados del Segundo Boom, a partir del año 1987, con el inicio de los primeros vuelos internacionales, cuando se incorpora con un carácter fundamentalmente especulativo al subsector turístico-inmobiliario. Así quedó expresado en un informe publicado por el periódico Canarias 7 (1988), en el que se preveía la construcción de 44.674 camas en la Isla para el periodo 1988-1995, añadiéndose otras 20.000 que en aquel entonces no se encontraban programadas, "por lo que en 1995 La Palma podría tener más de 60.000 camas" (Hernández, 2000:337). En julio de 1993, las previsiones turísticas para La Palma eran de 59.053 camas, una oferta semejante a la de otras islas Canarias marcadamente turísticas (Cabildo, 2001:41). La Palma tenía más suelo clasificado para fines turísticos que todas las plazas extra hoteleras de Tenerife en 1990. Con 17 veces más plazas previstas que las que en ese momento estaban en servicio en la Isla (Hernández, 2000:116). El director del Plan Insular de Ordenación, Álvaro Hernández, indicaba en 1992 como "hoy en La Palma hay unas 5.000 camas turísticas y tenemos planeamiento para 65.000, [esto suponía] multiplicar por 11 lo que ahora tenemos [...] de estas, 28.000 disponen ya de planeamiento consolidado [...] Tenemos como mucho, capacidad para desregular unas 30.000 camas" (Hernández Gómez, 1994:74). El incremento anual en el número 
de plazas alojativas entre los años 1992-1996 y 1996-2000, se produce con un decrecimiento de la demanda, 10,2 \% entre 1992-1996 y 4,3\% para el intervalo 1996-2000. Esta contradicción se explicó por la existencia de expectativas de plusvalías urbanísticas" (Cabildo, 2001:100). Las Islas Verdes y La Palma a la cabeza, lideraban en el año 2000 el crecimiento de la capacidad alojativa en el Archipiélago. La Palma con tasas para este año del 40,8 \%, se incorporaba en este momento al modelo turístico de litoral (Simancas, 2015:67-68). Un informe interno de la Viceconsejería de Turismo indicaba que la isla de La Palma, a febrero del 2001, tenía 8.496 plazas ejecutadas o en funcionamiento, 10.533 plazas sin ejecutar potenciales y 30.395 plazas expectantes, según planeamiento urbanístico. Las plazas expectantes en La Palma situaban a la Isla en el cuarto puesto del ranking en este aspecto del Archipiélago, por delante incluso de una isla turística como Lanzarote. La Palma tenía, en definitiva, unas expectativas de materializarse, si sumamos lo potencial a lo existente de 40.928 plazas, siendo la quinta isla turística del Archipiélago, muy por delante de sus dos compañeras "Verdes": La Gomera 18.154 y El Hierro 15.364 plazas (Simancas, 2015:123). Por tanto, La Palma en el cambio de milenio respondía perfectamente al contexto que caracterizó en gran medida el Tercer Boom Turístico (1997-2007), donde las expectativas de plazas contenidas en proyectos no materializados incidían de manera decisiva en un incremento insostenible de su capacidad alojativa.

Es por ello por lo que, en medio de estas expectativas insulares de crecimiento, el conocimiento a principios del 2001 del Borrador de Proyecto de Ley de Medidas Cautelares por el que el Gobierno Autónomo pretendía suspender el incremento de la oferta alojativa en toda Canarias tuvo en La Palma una oposición frontal por parte de sus principales sectores socioeconómicos. Estos solicitaron con insistencia un trato excepcional, considerando que el escenario de crecimiento en esta isla no se había producido. Pues, aunque reconocían la presencia de un incipiente desarrollo inmobiliario-turístico desde finales de la década de los 80 , este incremento era valorado por las autoridades y sectores económicos insulares como un modesto aumento sin sobrepresión territorial, al no encontrase materializadas ni la mitad de las plazas alojativas turísticas que se incluían en su planeamiento.

El mantenimiento de estas expectativas inmobiliario-turísticas explican las reclamaciones de las autoridades palmeras y de los principales sectores empresariales insulares contra las sucesivas normas controladoras del incremento de plazas. Estas perspectivas y una esperada y relativa intensificación del subsector de la construcción vinculado al turismo se convierten en estos años en los pilares para mantener una economía insular que continuamente se tambaleaba inmersa en una compleja reforma de su subsector económico fundamental, la agricultura platanera.

\section{LA MORATORIA (DECRETO 4/2001) Y SU RECEPCIÓN EN LA ISLA}

La amenaza de un posible alud de solicitudes y concesiones de autorizaciones previas de licencias urbanísticas en toda Canarias, en un escenario inmediato de suspensión del crecimiento inmobiliario-turístico, obligó al Gobierno regional a legislar con premura el Decreto 4/2001, de 12 de enero (BOC 7, 15/01/2001). También conocido como "Moratoria", suponía un parón relativo y temporal a la construcción turística y suspendía las autorizaciones y licencias urbanísticas durante un año, prorrogable otro. Ahora bien, este Decreto va a actuar 
en las Islas Verdes con flexibilidad: la interrupción de las actuaciones aprobadas o en trámite en estas islas sólo afectarían a los proyectos turísticos durante seis meses, prorrogables hasta un máximo de un año. Estamos, ante el primer trato diferencial con estas islas, sostenido en la consideración de que en ellas acontecía un "modelo específico" que generaba una "diferencia del nivel de renta per cápita respecto de las restantes islas" (BOC 7, 15/01/2001).

Los Cabildos de El Hierro y La Gomera, anteponiendo oficialmente el interés general, pero realmente menos damnificados dentro de las Islas Verdes por la medida, aceptaron las condiciones del Decreto. En cambio, el Cabildo de La Palma, en una situación diferente en cuanto a plazas expectantes, no aceptó en un primer momento ni siquiera la reducción a seis meses, mostrando un rechazo frontal al Decreto al que declararon injusto e insistiendo en que no existían razones objetivas que justificaran la aplicación de la Moratoria en La Palma: "el Gobierno de Canarias ha decidido aplicar un tratamiento contra la obesidad para unas islas que padecen anorexia”, apuntó el presidente insular (La Opinión, 16/01/2001, p.15).

El Cabildo palmero, que incluso llegó a considerar recurrir el Decreto, al final acabó aceptando los términos de la regulación, tras el compromiso del Gobierno regional de sustituir "La Moratoria" por una ley que incluía directrices específicas de actuación en cuanto a su desarrollo turístico. El anuncio de esta norma particular que les permitiría escapar de la suspensión, así como el colchón que suponía las en torno a 2.000 plazas con autorización previa a la promulgación del Decreto, pacificó el conflicto. El Cabildo de La Palma y el Gobierno regional (representado por su vicepresidente Adán Martín), comenzaron entonces a trabajar, con asperezas, en un nuevo modelo turístico específico para La Palma7.

Fruto de este trabajo fue el documento Compromiso por el Desarrollo Sostenible de Canarias (2001), también conocido como "Documento Verde" (Gobierno de Canarias, s/f), que indicaba la forma de actuación: "construir juntos un modelo especial para la isla de La Palma, porque son los ayuntamientos y el Cabildo los que tienen que definir ese modelo especial y el Gobierno arbitrar todas las medidas y asegurar la coherencia de los modelos de las siete islas, para que el modelo global de Canarias funcione", afirmó el Vicepresidente regional Adán Martín8 (Diario de Avisos, 24/02/2001, p.21).

En el Compromiso se hacía hincapié en la importancia del turismo rural, estudiando la posibilidad de tolerar la gran cantidad de camas ilegales que en este momento se comercializaban en La Palma, que estas incluso pudieran ser legalizadas y que muchas construcciones rurales de calidad, con menos de 50 años, pudieran tener un uso turístico. El Gobierno regional incorporó igualmente medidas para que la suspensión cautelar de licencias (cues-

7 Aun así, el Decreto 4/2001 tuvo consecuencias en la gestión del territorio insular. Se suprimió el Plan General de Tijarafe por contener crecimientos de la planta alojativa turística contrarios a la norma (COTMAC 03/01, 12/03/01).

8 Se trataba de un documento, sujeto a modificaciones, por tanto, flexible y adaptable a las circunstancias específicas de cada una de las islas. Liderado por el vicepresidente del Gobierno y Consejero de Economía y Hacienda, Adán Martín, el también denominado Itinerario A o Vía de Consenso, según el profesor Simancas (2015:113-128), fue uno de los dos modelos de actuación diseñados para resolver el problema de la presión urbano-turística sobre el territorio. Su idea era poner en común y pactar con las administraciones locales y agentes sociales una salida al problema de forma particular, es decir isla a isla. En contra, el llamado Itinerario B o Vía Normativa apostaba por una solución regional sin excepciones particulares de corte insular. La presidencia del Cabildo Insular palmero, que lo era también en este momento de la Federación Canarias de Islas (FECAI), fue uno de los mayores valedores del Itinerario A. 
tión derivada del Decreto de Moratoria) se pudieran levantar de forma rápida, ordenada y controlada de acuerdo con la propuesta que hiciera cada Isla. Estas medidas fueron consentidas, pero no colmaron plenamente las expectativas insulares. Desde el Cabildo se siguió insistiendo en dar vía libre a la creación de nuevas plazas turísticas, un planteamiento que se sostenía en documentos como el Plan Insular de Ordenación (PIOLP), en ese momento en aprobación inicial, que indicaba un tope de 27.000 plazas y el Plan Estratégico para el Desarrollo Sostenible de la Isla, que apuntaba 18.810 (Cabildo, 2000:110).

\section{EL DECRETO 126/2001, LA CONSOLIDACIÓN DE LAS ESPECIFICIDADES INSULARES POR PARÁLISIS DEL CRECIMIENTO TURÍSTICO}

La suspensión por el Tribunal Superior de Justicia de Canarias (TSJC) del Decreto 4/2001, modificó de nuevo el escenario regional. Esta sentencia llevó al Gobierno regional a aprobar el denominado "contra Decreto", en un intento de salvar el ya comentado objeto paralizador de la Moratoria. El Decreto 126/2001, de 28 de mayo (BOC 66, 28/05/2001), suspenderá la vigencia de las determinaciones turísticas de los Planes Insulares de Ordenación y de los Instrumentos de Planeamiento Urbanístico, pero vuelve a mantener con las Islas Verdes un trato especial. Argumentando ahora no inferior renta, como sucedió con el Decreto 4/2001, sino una escasa aspiración de crecimiento turístico en estas islas, el Decreto 126/2001 consideró que la pretensión del 3,1\% total para nuevas plazas turísticas en las Islas Verdes (entre el 2001 y 2003) no era una situación que justificara su aplicación. En concreto para La Palma se estimó que un crecimiento potencial en dos años de 1,8 \% la dejaba fuera de la situación de "extrema urgencia" que justificaba las medidas restrictivas del "contra Decreto".

Esta nueva excepcionalidad fue valorada positivamente por distintos sectores políticos y empresariales palmeros, recibiendo el rechazo de los colectivos ecologistas. Estos últimos, solicitaron la ampliación de la Moratoria a las Islas Verdes, considerando que el porcentaje utilizado para su aplicación singular era falso, al no contabilizarse la oferta turística clandestina.

\section{LA LEY 6/2001, EL DESARROLLO DE LA ACTIVIDAD TURÍSTICA VÍA PLAN TERRITORIAL ESPECIAL Y EL ANUNCIO DE UNA LEY ESPECÍ- FICA PARA LAS ISLAS VERDES EN MATERIA DE ORDENACIÓN DEL TURISMO}

Casi de manera inmediata al Decreto 126/2001, el Gobierno regional aprueba la Ley 6/2001 (BOC 92, 26/07/2001). Esta Ley suspendía la tramitación y aprobación de planes, de proyectos de ejecución, así como el otorgamiento de autorizaciones previas y licencias, mientras se redactaban las Directrices de Ordenación General y del Turismo (Villar, 2016:38). Una norma que insistió en tener una especial consideración con las Islas Verdes, por la menor dimensión de su oferta turística y por una situación económica y demográfica diferenciada en el contexto regional. En concreto, en forma de disposición adicional, se estableció la necesidad de fijar un régimen especial, por el que, en tanto no se aprobaran sus respectivos Planes Insulares de Ordenación, adaptados a las Directrices de Ordenación Gene- 
ral y del Turismo de Canarias, los Cabildos insulares podrían formular y tramitar un Plan Territorial Especial Turístico que las excluía de las medidas cautelares recogidas en esta Ley.

Con ámbito insular, este Plan Territorial Especial tendría vigencia hasta la aprobación de los Planes Insulares de Ordenación correspondientes y, en su defecto, por un plazo máximo de dos años establecería las previsiones específicas de desarrollo turístico bajo unos presupuestos que debían justificarse en función de las características económicas, sociales y territoriales de cada isla ${ }^{9}$. La aprobación inicial y provisional de este Plan Territorial Especial correspondería a las instituciones insulares, mientras que la aprobación definitiva sería potestad del Gobierno de Canarias, previo informe de la Comisión de Ordenación del Territorio y Medio Ambiente de Canarias (COTMAC) ${ }^{10}$.

Además el Gobierno regional también se comprometió, en la misma disposición adicional y "en el plazo de dos meses", a sacar adelante un nuevo proyecto de Ley que establecía las excepciones y contenidos legales que permitieran instaurar en las Islas Verdes un modelo de desarrollo sostenible propio y un desarrollo turístico específico, adelantando lo que luego se convertirá en una auténtica novedad en el ordenamiento territorial canario, la posibilidad de instalar en suelo rústico unidades aisladas de explotación turística integradas y respetuosas con el paisaje agrario.

El Cabildo Insular de La Palmas se mostró ilusionado por este contenido y especialmente celebró el anuncio de un proyecto de ley específico sobre su ordenación turística que le permitía no sólo eludir la Moratoria, sino obtener una de sus históricas reivindicaciones: que el diseño y tratamiento insular del turismo fuera realizado por las autoridades insulares. La patronal (CEPYME-La Palma) y el Centro de Iniciativas Turísticas (CIT-La Palma) aplaudieron las medidas indicadas, apresurándose a instar al Cabildo a que de manera urgente formulara el referido Plan Territorial Especial, para así retomar "los proyectos de carácter turístico que se vieron paralizados y que tan necesarios son" (Diario de Avisos, 27/10/2001, p.21). De igual forma se pidió celeridad en la aprobación del régimen legal especial previsto en la Ley 6/2001, ante la "situación de incertidumbre en la que se debate el futuro económico y social de la Isla [...] en un momento de encrucijada respecto al mantenimiento del sector agrario"11 (Diario de Avisos, 15/01/2001, p. 18).

9 El objetivo de este Plan era establecer criterios de localización de la oferta y condiciones para el traslado de capacidad de alojamiento a otro emplazamiento, el número y calidad de las plazas alojativas de nueva creación susceptibles de ser implantadas en la Isla, así como las bases para la posible reclasificación y recalificación, por el planeamiento general, de los sectores y ámbitos de suelo con fin turístico.

10 Órgano de deliberación, consulta y decisión de la Administración Pública de la Comunidad Autónoma de Canarias en materia de ordenación del territorio y medio ambiente.

11 El alcalde de Santa Cruz de La Palma sintetizó el parecer respecto al cambio de modelo económico que se vislumbraba en la Isla. "Ahora mismo vivimos fundamentalmente del sector primario, del plátano. No estamos hablando del turismo que se está haciendo en otras Islas, en primer lugar, porque La Palma no lo soportaría. Por mucho que sean establecimientos de cinco estrellas o de lujo, la Isla no puede soportar un número ilimitado de camas. Además, no tenemos infraestructuras preparadas para el turismo. Por ejemplo, no tenemos un campo de golf o un puerto deportivo. Queremos que venga un turismo de clase y a la vez no nos damos infraestructuras. Pero preguntamos qué se puede hacer para evitar que se vendan las plataneras. Es que sabemos que muy pronto el plátano no va a tener las ayudas que tiene actualmente y eso va a significar una disminución enorme de los ingresos de las personas y del producto interior bruto de nuestra Isla. Por lo tanto, habrá que llevar a la economía a otro lado. Yo no digo que haya que arrancar las plataneras, pero previniendo que eso va a ocurrir tenemos que tener en cuenta lo que queremos para esas zonas de medianías, que se pueden incluir dentro de un turismo racional, que no tiene que ser contradictorio con el modo de vida al que estamos habituados" (El Día, 12/06/2001, p. 12). 


\section{LA LEY ESPECIAL PARA LAS ISLAS VERDES (LEY 6/2002)}

La Ley Especial para La Palma, La Gomera y El Hierro, también conocida como "Ley de Islas Verdes", fue una norma muy debatida. El Colegio de Arquitectos de Canarias (COAC), conforme al contenido del borrador y en defensa de las especiales condiciones naturales de estas islas, denunció una situación inminente de "sobreexplotación" turística. Matizaba no obstante este colegio profesional, que en caso de creación de nuevas plazas debían descansar sobre el patrimonio tradicional existente, en todo caso rehabilitado, pero nunca sobre nuevos establecimientos turísticos ubicados en el paisaje rural (El Día, 27/05/2002, p. 18). El movimiento ecologista también se opuso desde el inicio, por tratarse de la consolidación de la ocupación especulativa del suelo rústico para actividades turísticas, suponiendo con ello la destrucción de los objetivos para los que estaba destinado este tipo de suelo. Igualmente denunció que se trataba de un proyecto legislativo a la carta, que había "nacido desde CC [Coalición Canaria] en La Palma, motivada por presiones y fuertes intereses en iniciar lo antes posible procesos urbanizadores en suelo rústico [...] una Ley hecha para La Palma y en concreto para una parte de la Isla, y la inclusión de La Gomera y El Hierro es pura literatura" (La Opinión de Tenerife, 31/05/2002, p. 26).Otra de las voces críticas con el anteproyecto de Ley fue la Asociación para el Desarrollo Rural de la Isla de La Palma (ADER-La Palma). Esta Asociación argumentó que las medidas que recogía el documento podrían entrar en contradicción con los planteamientos consensuados por los colectivos económicos y sociales y las distintas administraciones, durante el proceso de planificación estratégica que dio lugar al Plan de Desarrollo Sostenible de La Palma. Señalaban, que ningún espacio agrario insular significativamente productivo debería verse menoscabado por la injerencia de una actividad como la turística, que le es extraña y que sustancialmente entraba a competir con sus recursos: agua y suelo (Diario de Avisos, 31/05/2002, p. 20).

El CIT-La Palma y CEPYME La Palma apoyaron el Proyecto de Ley, pero exigieron profundas revisiones tendentes al aumento de la oferta. El Cabildo palmero, en esa línea de máximos, se alió con buena parte de las propuestas empresariales e insistió de forma reiterada en la aprobación de la Ley, incluso solicitando la vía parlamentaria del trámite abreviado por extrema necesidad, acudiendo a la urgente situación en la que se encontraba la actividad agraria de exportación en la Isla. Y es que, independientemente de la difícil situación en la que se hallaba la comercialización del plátano, toda esta controversia acontecía en un clima de ansiedad y presión institucional y empresarial, al no poder materializarse una serie de proyectos que esperaban largo tiempo para su realización.

Definitivamente, el Parlamento Canario aprobó el proyecto de Ley en junio del 2002, haciendo caso al mandato establecido en la Ley 6/2001 y más en concreto a su disposición adicional primera. A través de la Ley 6/2002, sobre Medidas de Ordenación Territorial de la Actividad Turística en las islas de El Hierro, La Gomera y La Palma (BOC 89, $1 / 07 / 2002$ ), se procedió a modular en estas tres islas "no turísticas" las normas generales aplicadas en el resto del Archipiélago, consagrándose mecanismos específicos de regulación del sector como consecuencia de una menor dimensión de su oferta turística. De esta forma se recogía una de las históricas demandas palmeras, el reconocimiento de su "hecho 
diferencial", sentando un precedente en Canarias, en tanto que se trataba de la primera vez que se legislaba en materia territorial exclusivamente para una parte de la Comunidad ${ }^{12}$.

Con el paisaje como elemento identificador de la oferta y con la idea de preservar unas islas identificadas por su valores patrimoniales, se dejaba en manos de los Cabildos Insulares respectivos la capacidad de formular y tramitar, en tanto no se aprobaran los Planes Insulares adaptados a unas futuras Directrices de Ordenación Sectorial del Turismo, un Plan Territorial Especial de ámbito insular, que englobará las normas de aplicación directa, directivas y recomendaciones necesarias para su desarrollo turístico.

La Ley 6/2002, se planteó bajo la consideración de que una desigual implantación de la actividad turística entre islas había motivado un dispar desarrollo económico insular, y con éste, importantes desequilibrios sociales entre las islas de histórica implantación turística y las que no habían tenido a este sector como hegemónico. Así, con la finalidad de generar un desarrollo económico y social duradero, compatible con la conservación de los recursos naturales y en la línea de incrementar la calidad de vida de forma territorialmente equilibrada en todo el Archipiélago, la Ley 6/2002 indujo al crecimiento económico y demográfico de las Islas Verdes apartándose del modelo urbanístico basado en la urbanización turística litoral, fundamento del modelo de las Islas Turísticas. Se proyectó entonces para las Islas Verdes el desarrollo de la oferta en suelo rústico, en forma de "unidades aisladas de explotación turística, integradas en el medio y respetando el paisaje agrario", toda una novedad en la legislación turística canaria.

De esta forma, la excepcionalidad no sólo se concretó permitiendo un desarrollo turístico vinculado al medio natural y complementario a las actividades agropecuarias, en contraposición a la tradicional oferta de turismo de litoral convencional dominante en el Archipiélago. Sino que además se daba rienda suelta, salvo expresa prohibición del planeamiento, a la utilización del suelo rústico con fines turísticos, especialmente en suelos categorizados como suelos rústicos de asentamientos rurales y agrícolas. Unos suelos que, aunque predispuestos por su definición a un uso residencial y eventualmente de ocio, por la existencia de una previa situación edificatoria, eran, especialmente en el caso concreto del suelo rústico de asentamiento agrícola, suelos que poseían limitaciones jurídicas que ponderaban la proporción y características de la edificación a la magnitud de la explotación primaria que en él se ejecutara.

Cuestión aparte planteaba la ubicación turística en otras categorías de suelo rústico. Especialmente delicada era la materialización de esta actividad en suelos rústicos de

12 Esas particularidades recogidas en la Ley de las Islas Verdes se mantendrán en el desarrollo legislativo posterior. Así, la Ley 19/2003 o de Directrices de Ordenación General y del Turismo de Canarias (BOC 73, $15 / 04 / 2003)$, para las Islas Verdes dispuso que su contenido quedara como complementario a lo establecido en la Ley 6/2002. De forma semejante se mostró la Ley 6/2009, de 6 de mayo, de Medidas urgentes en materia de ordenación territorial para la dinamización sectorial y la ordenación del turismo (BOC 89, 12/05/2009), justificándose en las "peculiares circunstancias" de las Islas Verdes. En la Ley 14/2009, que modifica la Ley 7/1995, de ordenación del turismo en Canarias (BOC 2,5/10/10) se dictaron normas exclusivas para edificaciones aisladas en suelo rústico exclusivamente para las Islas Verdes y se modifica la Ley 6/2002. La Ley 2/2013, de 29 de mayo, de Renovación y modernización turística de Canarias (BOC 103, 31/05/2013), manifestó, en su exposición de motivos, que en las Islas Verdes la actividad turística tenía una regulación singular, la recogida en la Ley 6/2002. La Ley 14/2014, de armonización y simplificación en materia de Protección del Territorio y de los Recursos Naturales (BOC 2,5/01/2015), insiste en especificar la ordenación turística en las islas de El Hierro, La Gomera y La Palma en una nueva modificación de la Ley 6/2002. 
protección agraria, constituida esta categoría para la ordenación del aprovechamiento del potencial agrícola, ganadero y piscícola. O la implantación en suelos rústicos de protección paisajística, suelo para la conservación del valor paisajístico, natural, antropizado y de las características fisiográficas de los terrenos. Sobre estos suelos la excepcionalidad apostó por tendencias protectoras y usos compatibles con sus características, aceptando la implantación de la actividad turística como forma de adquisición de rentas complementarias al sector primario, en un intento de evitar su desaparición ante procesos de abandono creciente.

Ahora bien, la Ley que proponía una distribución de las rentas de la actividad turística sobre un suelo de vocación primaria y paisajística, al pasar éste a tener naturaleza urbanística, obligó, para mantener la condición de estos suelos y por el deber de conservar una determinada actividad agrícola y un paisaje característico, a regular la construcción de las infraestructuras alojativas allí implantadas, convirtiéndose en su principal problema.

\section{EL PLAN TERRITORIAL ESPECIAL TURÍSTICO DE LA PALMA (PTETLP)}

\subsection{Las dificultades para concretar el documento}

En ausencia del Plan Insular de Ordenación (PIOLP) ${ }^{13}$, en un clima de agitación inmobiliaria, apoyado en las disposiciones adicionales primeras de las Leyes 6/2001 y 6/2002, el Cabildo procedió a la redacción del preceptivo Plan Territorial Especial Turístico de La Palma (PTETLP), como una forma, en palabras de sus dirigentes, de "no estar metido en la moratoria" (El Día, 26/10/2002, p. 23) y "favorecer y facilitar la construcción y el desarrollo turístico que este territorio demanda", evitando la parálisis administrativa que "está generando que los inversores, que se encuentran con todo tipo de dificultades, se están marchando de la Isla" (El Día, 15/09/2002, p. 30) ${ }^{14}$.

Responsabilidad del Cabildo Insular, este Plan se convirtió en un problema sociopolítico de primer orden, al tener que conciliar en su contenido los intereses, deseos y voluntades de los municipios por un lado y de los agentes económicos insulares por otro. $\mathrm{Y}$ es que para acordar un Plan consensuado y llegar a la cifra total inicialmente prevista de entre 20.000 y 30.000 plazas turísticas, los dos municipios con mayor implantación turística (Breña Baja y Los Llanos de Aridane), debían realizar las mayores renuncias en materia de nuevas plazas alojativas. Los núcleos de Los Cancajos (Breña Alta) y Puerto Naos (Los Llanos de Aridane), acaparaban en ese momento más del 60 por ciento de las plazas insulares. Estos municipios, junto con Tazacorte y Fuencaliente, eran los que tenían más planes parciales y camas pendientes de ejecución o aprobación. Ahora bien, la práctica totalidad de los municipios tenían previsto al menos un proyecto de complejo destinado a explotación turística. El problema del reparto se convirtió en objeto central de discusión.

Otra cuestión controvertida fue la consideración de las camas ilegales. El Cabildo, desde hacía años, negociaba con el Gobierno regional dar encaje a las plazas alojativas que sin cobertura legal operaban en La Palma. Sobre una cifra superior a las 3.000 plazas,

13 El PIOLP se aprobó definitivamente en abril del 2011 y mantendrá un rol secundario hasta la anulación del PTETLP.

14 Según CEPYME- La Palma la isla tenía "ancladas" inversiones por valor de más de 180 millones de euros (Canarias7, 26/02/2004, p.37). 
el aspecto fundamental se centraba en evitar que esta planta alojativa ilegal, en su paso a legal, computara como crecimiento de la oferta turística, evitando con ello que la Isla se quedara sin margen de progresión inmobiliaria.

Por último, la tercera gran cuestión fue la construcción de campos de golf. Se consideró imprescindible para el crecimiento turístico la construcción de varios campos, apostando por dar viabilidad a algunos proyectos que en este momento estaban en curso. Situados en los municipios de Fuencaliente, Los Llanos de Aridane, Breña Alta, Puntagorda y Barlovento, los cinco campos de golf planificados debían llevar aparejados, para "que haga rentable el capital destinado a la actuación” (El Día, 9/01/2004, p. 23), instalaciones alojativas.

\subsection{Tramitación y aprobaciones parciales}

En febrero del 2004 se presenta el Avance del PTETLP, en el que se estableció una cifra de 25.500 camas alojativas para la Isla hasta el año 2020. Un incremento relevante, pues la oferta hasta este año era 8.445 plazas (Promotur, 2018).

El problema de la distribución municipal de los alojamientos turísticos se contempló creando cinco zonas a las que se le asignaba una carga turística en función de parámetros como: población, medio ambiente y espacios naturales. El 60 por ciento de la isla quedaba exenta de la oferta turística. Las zonas 1 (Los Llanos de Aridane, Tazacorte y El Paso) y 2 (Santa Cruz de La Palma, Breña Alta, Breña Baja, Mazo y Fuencaliente), concentraron el mayor número de plazas, en un reparto que no coincidía con las previsiones municipales. Cuando se abrió el correspondiente periodo de exposición pública llovieron las críticas, presentándose decenas de escritos de alegaciones por parte de ayuntamientos, entidades y particulares. Un proceso público que provocó duras tensiones y oposición en torno a la localización y ritmo de crecimiento de la oferta alojativa, corriendo el PTETLP el peligro de desmoronarse nada más empezar.

Finalmente, la aprobación inicial sale adelante (junio del 2004), únicamente con los votos del grupo de gobierno insular, Coalición Canaria (CC), con discrepancias entre los municipios por el reparto y con la oposición de la Demarcación en La Palma del Colegio de Arquitectos de Canarias y la Viceconsejería de Ordenación del Gobierno de Canarias, quienes elaboraron sendos informes en los que manifestaban relevantes críticas formales y de contenido al Plan.

En prácticamente un año (mayo 2005), la Corporación insular procede a la aprobación provisional. Una decisión igualmente complicada, pues incluso en el último momento se tuvo que retrasar el inicio del Pleno donde definitivamente se aprobó, alargándose hasta el límite la Comisión que estudiaba las alegaciones al documento en un intento de llegar a una propuesta consensuada. Definitivamente se aprobó sin unanimidad en cuanto al reparto y pidiendo celeridad en la aprobación definitiva. La aceptación precipitada de algunas alegaciones hicieron que la Asamblea Ecologista de La Palma presentara más de 700 firmas pidiendo la apertura de un nuevo periodo de información pública y consulta, entendiendo que lo estimado en número y objeto suponía "una modificación sustancial del documento inicial" (El Día, 17/10/2005, p. 20).

Las actuaciones previstas en el documento provisional respondían a tres tipologías diferentes. Las actuaciones específicas (AEP) eran actuaciones aisladas en suelo rústico a 
las que se les exigía una adecuada articulación del viario, la canalización subterránea de las redes eléctricas, telefónicas y de abastecimiento, la depuración de aguas con instalación propia, criterios ambientales en el tratamiento de los espacios libres, paredes y ajardinado, así como criterios arquitectónicos, primando las formas y volúmenes que mejor se adecuaran a las características del lugar. Como deber urbanístico con el medio, vinculado a su existencia como explotación turística, se obligaba a recuperar el tradicional y característico espacio agrario y sus respectivos usos y aprovechamientos.

Tabla 3

ACTUACIONES ESPECÍFICAS PREVISTAS (AEP)

\begin{tabular}{|c|c|c|c|l|}
\hline DENOMINACIÓN & $\begin{array}{c}\text { LOCALIZACIÓN } \\
\text { (Municipio) }\end{array}$ & $\begin{array}{c}\text { CLASE Y } \\
\text { CATEGORÍA } \\
\text { DE SUELO }\end{array}$ & $\begin{array}{c}\text { INSTALACIÓN } \\
\text { ALOJATIVA } \\
\text { (Modalidad y } \\
\text { Categoría Mínima) }\end{array}$ & $\begin{array}{c}\text { PLAZAS } \\
\text { MÁXIMAS }\end{array}$ \\
\hline AEP 1. La Hiedra & El Paso & Suelo Rústico & Hotelera 4* & No establecida \\
\hline AEP 2. Tacande & El Paso & Suelo Rústico & Hotelera 4 $*$ & No establecida \\
\hline AEP 3. Los Quemados & Fuencaliente & Suelo Rústico & Hotelera 5* & 80 \\
\hline AEP 4. La Alegría & Breña Alta & Suelo Rústico & Hotelera 5* & No establecida \\
\hline AEP 5. D. Pedro & Garafía & Suelo Rústico & Hotelera 4 & 80 \\
\hline AEP 6. Las Lomadas & S. Andrés y Sauces & Suelo Rústico & Hotelera 4* & No establecida \\
\hline AEP 7. S. Andrés & S. Andrés y Sauces & Suelo Rústico & Hotelera 4 & No establecida \\
\hline
\end{tabular}

Fuente: Cabildo (2007).

Las Actuaciones Convencionales (ACP), se trataba de proyectos diseñados sobre diferentes clases de suelo, en el que se integrarán algunos sectores de Planes Parciales que habían quedado sin ejecutar (Finca Amado y Los Dragos), junto a actuaciones nuevas en suelos urbanizables anexos a núcleos residenciales aislados. Esta tipología debía reservar suelo para espacios libres públicos, utilizar preferentemente las infraestructuras de servicios existentes o enterrar las de nueva realización, depurar el agua con instalaciones propias y respetar el paisaje de la zona.

Tabla 4

ACTUACIONES CONVENCIONALES PROPUESTAS (ACP)

\begin{tabular}{|c|c|c|c|c|c|}
\hline DENOMINACIÓN & $\begin{array}{c}\text { LOCALIZACIÓN } \\
\text { (Municipio) }\end{array}$ & $\begin{array}{c}\text { CLASE Y } \\
\text { CATEGORÍA DE } \\
\text { SUELO }\end{array}$ & $\begin{array}{c}\text { INSTALACIÓN } \\
\text { ALOJATIVA } \\
\text { (Modalidad y } \\
\text { Categoría Mínima) }\end{array}$ & $\begin{array}{c}\text { PLAZAS } \\
\text { MÁXIMAS }\end{array}$ & CARACTERÍSTICAS \\
\hline $\begin{array}{c}\text { ACP-1 La } \\
\text { Cangrejera }\end{array}$ & Mazo & $\begin{array}{l}\text { Urbanizable } \\
\text { no sectorizado } \\
\text { turístico }\end{array}$ & Hotelera 4* & $\leq 500$ & $\begin{array}{l}\text { Actuación anexa } \\
\text { a núcleo urbano } \\
\text { residencial }\end{array}$ \\
\hline $\begin{array}{c}\text { ACP-2 Balcones } \\
\text { de Mazo }\end{array}$ & $\begin{array}{l}\text { Urbanizable } \\
\text { no sectorizado } \\
\text { turístico }\end{array}$ & Hotelera 5* & $\leq 500$ & Actuación aislada \\
\hline
\end{tabular}




\begin{tabular}{|c|c|c|c|c|c|}
\hline DENOMINACIÓN & $\begin{array}{c}\text { LOCALIZACIÓN } \\
\text { (Municipio) }\end{array}$ & \begin{tabular}{|c} 
CLASE Y \\
CATEGORÍA DE \\
SUELO
\end{tabular} & $\begin{array}{c}\text { INSTALACIÓN } \\
\text { ALOJATIVA } \\
\text { (Modalidad y } \\
\text { Categoría Mínima) }\end{array}$ & $\begin{array}{l}\text { PLAZAS } \\
\text { MÁXIMAS }\end{array}$ & CARACTERÍSTICAS \\
\hline $\begin{array}{c}\text { ACP-3 Finca } \\
\text { Amado }\end{array}$ & Breña Baja & $\begin{array}{l}\text { Urbano } \\
\text { consolidado } \\
\text { mixto } \\
\text { Urbanizable } \\
\text { sectorizado } \\
\text { ordenado }\end{array}$ & $\begin{array}{l}\text { Hotelera } 4 * \\
\text { Extrahotelera } 3 \\
\text { LL }\end{array}$ & $\leq 400$ & $\begin{array}{l}\text { Núcleo mixto, } \\
\text { comprende núcleo } \\
\text { urbano, sector } \\
\text { en proceso de } \\
\text { urbanización, } \\
\text { desarrollo planes } \\
\text { parciales Finca } \\
\text { Amado I y II }\end{array}$ \\
\hline $\begin{array}{c}\text { ACP-4 Los } \\
\text { Dragos }\end{array}$ & Breña Baja & $\begin{array}{l}\text { Urbanizable } \\
\text { sectorizado } \\
\text { ordenado } \\
\text { turístico }\end{array}$ & Hotelera $4 *$ & $\leq 417$ & $\begin{array}{l}\text { Sector en proceso } \\
\text { de urbanización, } \\
\text { desarrollo del plan } \\
\text { parcial Los Dragos }\end{array}$ \\
\hline $\begin{array}{c}\text { ACP-5 Martín } \\
\text { Luis }\end{array}$ & Puntallana & $\begin{array}{l}\text { Urbanizable } \\
\text { no sectorizado } \\
\text { turístico }\end{array}$ & Hotelera $4 *$ & $\leq 480$ & $\begin{array}{l}\text { Actuación } \\
\text { aislada en suelo } \\
\text { urbanizable } \\
\end{array}$ \\
\hline $\begin{array}{c}\text { ACP 6- Santa } \\
\text { Lucía }\end{array}$ & Puntallana & $\begin{array}{l}\text { Urbanizable } \\
\text { sectorizado } \\
\text { ordenado } \\
\text { turístico }\end{array}$ & Hotelera $5 *$ & $\leq 250$ & $\begin{array}{l}\text { Actuación } \\
\text { aislada en suelo } \\
\text { urbanizable }\end{array}$ \\
\hline $\begin{array}{c}\text { ACP 7- La } \\
\text { Tahona }\end{array}$ & Tijarafe & $\begin{array}{l}\text { Urbanizable } \\
\text { no sectorizado } \\
\text { turístico }\end{array}$ & $\begin{array}{l}\text { Hotelera } 5 * \\
\text { Extrahotelera } 4 \\
\text { LL }\end{array}$ & $\leq 600$ & $\begin{array}{l}\text { Actuación } \\
\text { aislada en suelo } \\
\text { urbanizable }\end{array}$ \\
\hline $\begin{array}{l}\text { ACP 8- Vista } \\
\text { Alegre }\end{array}$ & El Paso & $\begin{array}{l}\text { Urbanizable } \\
\text { no sectorizado } \\
\text { turístico } \\
\end{array}$ & Hotelera $4 *$ & $\leq 500$ & $\begin{array}{l}\text { Actuación anexa a } \\
\text { núcleo urbano }\end{array}$ \\
\hline $\begin{array}{c}\text { ACP 9- Las } \\
\text { Hoyas }\end{array}$ & Tazacorte & $\begin{array}{l}\text { Urbanizable } \\
\text { no sectorizado } \\
\text { turístico } \\
\end{array}$ & Hotelera $4 *$ & $\leq 900$ & $\begin{array}{l}\text { Actuación } \\
\text { aislada en suelo } \\
\text { urbanizable } \\
\end{array}$ \\
\hline $\begin{array}{c}\text { ACP 10- Hoyo } \\
\text { Verdugo }\end{array}$ & Tazacorte & $\begin{array}{l}\text { Urbanizable } \\
\text { sectorizado } \\
\text { ordenado } \\
\text { turístico } \\
\end{array}$ & Hotelera $4 *$ & $\leq 500$ & $\begin{array}{l}\text { Actuación aislada } \\
\text { en suelo rústico }\end{array}$ \\
\hline $\begin{array}{c}\text { ACP 11- El } \\
\text { Puerto }\end{array}$ & Tazacorte & $\begin{array}{l}\text { Urbano no } \\
\text { consolidado } \\
\text { Urbanizable } \\
\text { no sectorizado } \\
\text { turístico }\end{array}$ & Hotelera $5^{*}$ & $\leq 500$ & $\begin{array}{l}\text { Actuación anexa a } \\
\text { núcleo urbano }\end{array}$ \\
\hline $\begin{array}{l}\text { ACP } 12 \text { - } \\
\text { Tazacorte }\end{array}$ & Tazacorte & $\begin{array}{l}\text { Urbanizable } \\
\text { no sectorizado } \\
\text { turístico } \\
\end{array}$ & Hotelera $4 *$ & $\leq 235$ & $\begin{array}{l}\text { Actuación anexa a } \\
\text { núcleo urbano }\end{array}$ \\
\hline $\begin{array}{c}\text { ACP } 13 \text { - Las } \\
\text { Manchas }\end{array}$ & $\begin{array}{l}\text { Los Llanos de } \\
\text { Aridane }\end{array}$ & $\begin{array}{l}\text { Urbanizable } \\
\text { no sectorizado } \\
\text { turístico }\end{array}$ & Hotelera $4 *$ & $\leq 500$ & $\begin{array}{l}\text { Actuación } \\
\text { aislada en suelo } \\
\text { urbanizable }\end{array}$ \\
\hline
\end{tabular}

Fuente: Cabildo (2007). 
La última de las tipologías fueron las Actuaciones Estratégicas Singulares (SDO), fundamentadas para la ejecución de los campos de golf e instalaciones alojativas anexas en suelo rústico. Se exigía para esta tipología una adecuada articulación territorial con el viario general, utilizándose preferentemente las vías existentes. Las instalaciones alojativas debían tener una tipología compacta a semejanza de las tradicionales, utilizar las infraestructuras de servicios presentes y enterrar aquellas redes que se demanden, todo ello en perfecta adecuación con el paisaje.

\section{Tabla 5 \\ ACTUACIONES ESTRATÉGICAS SINGULARES (SDO)}

\begin{tabular}{|c|c|c|c|c|}
\hline DENOMINACIÓN & $\begin{array}{c}\text { LOCALIZACIÓN } \\
\text { (Municipio) }\end{array}$ & $\begin{array}{c}\text { CLASE Y } \\
\text { CATEGORÍA } \\
\text { DE SUELO }\end{array}$ & $\begin{array}{c}\text { INSTALACIÓN } \\
\text { ALOJATIVA } \\
\text { (Modalidad y } \\
\text { Categoría Mínima) }\end{array}$ & PLAZAS \\
MÁXIMAS \\
\hline $\begin{array}{c}\text { SD1- Campo de Golf y } \\
\text { actuaciones aisladas }\end{array}$ & $\begin{array}{c}\text { Los Llanos de Aridane } \\
\text {-El Paso }\end{array}$ & Suelo Rústico & Hotelera 4 * & 576 \\
\hline $\begin{array}{c}\text { SD2-Campo de Golf y } \\
\text { actuaciones aisladas }\end{array}$ & Breña Baja & Suelo Rústico & Hotelera 4* & 316 \\
\hline $\begin{array}{c}\text { SD3- Campo de Golf y } \\
\text { actuaciones aisladas }\end{array}$ & Fuencaliente & Suelo Rústico & Hotelera 4* & 555 \\
\hline $\begin{array}{c}\text { SD4- Campo de Golf y } \\
\text { actuaciones aisladas }\end{array}$ & Barlovento & Suelo Rústico & Hotelera 4* & 269 \\
\hline $\begin{array}{c}\text { SD5- Campo de Golf y } \\
\text { actuaciones aisladas }\end{array}$ & Puntagorda & Suelo Rústico & Hotelera 4* & 248 \\
\hline
\end{tabular}

Fuente: Cabildo (2007).

Con un importante retraso sobre lo previsto (marzo de 2006), el Cabildo remitió el PTETLP a la COTMAC, recabando el informe preceptivo previo a su aprobación definitiva. La Comisión en sesión celebrada en La Palma (COTMAC 05/06, 22/06/2006), emitió un informe favorable sobre el PTETLP condicionado a la subsanación de una serie de reparos formales y materiales. En síntesis, debían recabarse informes vinculantes sobre: la zona aeroportuaria, costas, telecomunicaciones y carreteras. De igual forma, debían someterse a información pública las modificaciones introducidas en la aprobación provisional del Plan, por nueva incorporación, por su transformación de núcleo mixto a ACP o por incremento en el número de plazas. Cinco $\operatorname{ACP}(2,5,7,9$ y 13) debían asociarse a equipamientos complementarios que cualificaran su oferta turística, conforme a lo dispuesto en la Ley 19/2003 (BOC 73, 15/04/2003) y debían ser suprimidas o suspendidas hasta la previsión por el Cabildo Insular de sus correspondientes equipamientos ${ }^{15}$. Y, por último, la COTMAC, en tanto que órgano ambiental competente, declaró el PTETLP inviable, por incumplimiento de la ley de evaluación ambiental de planes o Ley 9/2006 (BOE102,

15 La Ley 19/2003 o de Directrices impedía la realización de instalaciones aisladas, fuera de núcleos turísticos tradicionales, a no ser que estos estuvieran vinculadas a proyectos que cualificaran la oferta turística. 
29/04/2006), así como por la no sujeción del Plan al proceso de evaluación ambiental establecido en el artículo 7 de la mencionada Ley.

En cuatro meses el Cabildo rectifica y saca a información pública lo condicionado por la COTMAC. A la par, para dar mayores garantías de ejecución de los planes previstos, se sometió a información pública un nuevo documento denominado Sostenibilidad y Viabilidad Económica de la Red Completa de Campos de Golf, en el que se trataba la construcción de las camas alojativas necesarias para que los inversores pudieran considerar rentable la ejecución de estos recintos deportivos e instalaciones anexas.

Ratificado por el Cabildo en mayo de 2007, sin unanimidad, se remite un nuevo PTETLP adaptado en parte al acuerdo de la COTMAC de junio de 2006 para su valoración. La Comisión ratificaba entonces una "parte fundamental" del Plan, dejando pendiente la tramitación de las plazas alojativas incorporadas o incrementadas, así como las cinco actuaciones suspendidas por carecer de equipamientos estructurantes vinculados. La Consejería de Medio Ambiente y Ordenación del Territorio del Gobierno de Canarias, conforme a esta recomendación de la COTMAC y mediante el Decreto 95/2007 (BOC 94, 10/05/07) aprueba parte el PTETLP, dejando el resto pendiente de subsanación. Ahora bien, la legalización de alrededor de 3.000 plazas alojativas y la posibilidad de ejecutar pequeños proyectos turísticos en el medio rural, aunque suponía un significativo adelanto de lo propuesto, solo suponía una aprobación parcial del Plan Territorial.

Esta aprobación parcial fue contestada por la patronal hotelera tinerfeña (Ashotel), quien formalizó una demanda en la que solicitaba la nulidad del Decreto, al normalizar este, vía régimen transitorio, miles de plazas ilegales carentes de licencias. Al recurso de Ashotel se le unió otro de la Asamblea Ecologista de La Palma, la Asociación Tinerfeña de Amigos de la Naturaleza y Ecologistas en Acción de La Palma, pidiendo igualmente la nulidad por incumplimiento de la Ley 9/2006, por vulnerar las Directrices (Ley 19/2003), ciertas previsiones de espacios naturales protegidos y por distintas actuaciones en varios sectores de suelo urbanizable ${ }^{16}$.También recurrieron el Decreto los ayuntamientos de Breña Alta, Barlovento, Puntallana y El Paso, al sentirse coartadas sus posibilidades de desarrollo urbanístico, por poner en peligro inversiones ya comprometidas en el planeamiento municipal y por haberse excedido el PTETLP en sus competencias al clasificar suelos (El Día, 31/07/2007, p. 25).

Los proyectos suspendidos encontraron poco a poco su justificación vinculándose a diversos equipamientos complementarios ${ }^{17}$.Y en septiembre de 2007, subsanadas las deficiencias advertidas en el Decreto 95/2007, se remite por el Cabildo Insular un nuevo PTETLP a la COTMAC. Este organismo, tras haber dejado en un primer momento sobre la mesa la decisión (COTMAC 08/07, 30/11/07), a principios del año 2008 (COTMAC 01/08, 18/01/08) analiza los reparos planteados al Decreto 95/2007. La COTMAC per-

16 Este recurso fue desestimado en el 2009 (Sentencia 92/2009, 30/04/2009).

17 Cualificando la oferta turística los proyectos obtuvieron acomodo conforme a la Ley de Directrices (19/2003). Teniendo en cuenta que debían tratarse de equipamientos relevantes en el que se incluía un hotel y no al revés, la ACP-9 se adhería a un parque temático sobre los fondos marinos, la ACP-2 se ligaba a un puerto deportivo, las ACP-13 y 7 proponían su desarrollo mediante sendos complejos de carácter sanitario, por último, la ACP-5, se planteó dentro del denominado Parque Temático de Martín Luis (Puntallana), centrado en la cultura insular. De igual forma se aprobaron, con discrepancias, los campos de golf y sus camas anexas. 
mitió entonces que los municipios palmeros pudieran desarrollar sus cascos urbanos de manera justificada y en función de las necesidades poblacionales, aunque para ello invadieran espacios que en el PTETLP se hubieran establecido para uso agrario o medioambiental. La Viceconsejería de Ordenación Territorial del Gobierno de Canarias publicó en el Boletín Oficial de Canarias (BOC 35, 18/02/2008) este acuerdo de la COTMAC, asumiendo el planteamiento de la Comisión y dando con ello luz verde a los desarrollos de los planes generales de los respectivos municipios. Quedaban así resueltos los agravios con los ayuntamientos anteriormente mencionados, retirando estos su recurso contra el Plan.

En una nueva Comisión (COTMAC 03/08, 3/04/08), se abordaron las Actuaciones Estratégicas Singulares (la implantación de los cinco campos de golf e infraestructura alojativa complementaria), la delimitación de los núcleos mixtos y las Actuaciones Convencionales que habían quedado pendientes en la sesión del 2006. Tras el análisis, la Comisión levantó la suspensión de estos proyectos y aprobó buena parte del PTETLP, condicionando 2.480 camas en 5 ACP $(2,5,7,9$ y13) a la subsanación de determinados reparos formales y materiales. De esta forma se dio luz verde a 9.500 camas más. Respecto a los campos de golf, la COTMAC admitió, con ciertos recelos, la implantación de los cinco campos de golf, aun cuando ciertos informes del Servicio de Ordenación Territorial indicaban que tales recintos originaban "impactos severos" en el entorno natural y el paisaje.

Este nuevo acuerdo de la COTMAC fue calificado por los ecologistas como una "irresponsabilidad". Y el CIT-Tedote, insatisfecho por el número de camas aprobado, concluyó en que lo aprobado no servía para nada: "que se pueden hacer cuatro campos [de golf], pero con unos condicionantes que no se puede hacer ninguno, porque son inviables, ya que: ¿quién invierte 50 o 60 millones para hacer un campo con sólo 300 camas?” (El Día, 5/04/2008, p.22).

El Consejo de Gobierno asumió lo decidido en la COTMAC y aprobó a través del Decreto 123/2008 (BOC 111, 5/06/2008) otra parte del PTETLP. Este nuevo empuje dinamizó las actuaciones urbanísticas. Los promotores de las actuaciones suspendidas se afanaron en acabar de definir en plazo los proyectos de equipamientos estructurantes vinculados a los alojamientos turísticos. Todos menos La Tahona en Tijarafe (ACP-7), que quedó excluida del PTETLP por acuerdo del Cabildo, al no contar con la justificación de su vinculación con un equipamiento estructurante. El resto de las ACP, con sus correspondientes equipamientos, fueron sometidas a información pública y definitivamente aprobadas en noviembre de 2008 por la mayoría nacionalista en el Cabildo, con el apoyo del PP y la abstención del PSOE.

La COTMAC 06/10 (28/07/2010) aprobó las ACP que quedaban pendientes y remitió al Consejo de Gobierno lo que aún quedaba del Plan. Este, tras cuatro años de tramitación, aprobaba definitivamente el PTETLP mediante el Decreto 120/2010 (BOC 180, 13/09/2010).

Ahora bien, los proyectos recogidos no se realizaron, caducando por distintas razones sus expedientes. La especulación, la paralización infructuosa en busca de un mayor número de camas y los problemas judiciales y urbanísticos, fueron algunas de las razones de su no ejecución en tiempo. Los cinco espacios autorizados para campos de golf tampoco se ejecutaron en fecha, pues las camas asociadas a estos eran inferiores a las inicialmente previstas por los promotores, porque en algunos casos afectaban a espacios naturales protegidos o porque su ubicación no se encontraba recogida en los correspondientes planes generales, instrumentos 
que en muchos casos se retrasaron en su adaptación. En cuanto a los tres puertos deportivos diseñados, el único realizado fue La Marina de Santa Cruz de La Palma. Ni siquiera las viviendas turísticas ilegales en suelo rústico regularizaron su situación. En 2015, de la potencial regularización de 3.406 plazas en situación de alegalidad solo se habían legalizado 200 .

De esta forma, trascurridos varios años, no sólo eran escasos los resultados palpables obtenidos, sino que muchas actuaciones contempladas en el Plan Territorial o estaban caducadas o estaban cerca de hacerlo. Ante esto, el Cabildo de La Palma procedió entonces a modificar algunos aspectos del PTETLP para favorecer que se pudieran desarrollar el mayor número de actuaciones posibles. Se reabre entonces el debate en torno al necesario aumento en el número de camas para que los proyectos fueran viables, así como la incorporación de nuevas instalaciones. Tendrán que pasar más de dos años (2015) para que el pleno del Cabildo de La Palma aprobara, por unanimidad, una modificación determinante del PTETLP, ofreciendo un nuevo plazo para las construcciones previstas.

\subsection{Su recorrido en los tribunales y definitiva anulación}

Desde finales del 2008 se precipitan los procedimientos judiciales contra el PTETLP. En octubre, el Tribunal Superior de Justicia de Canarias (TSJC) admitió a trámite el segundo contencioso presentado desde las asociaciones ecologistas. Seis meses después este mismo colectivo presentará un tercer contencioso contra el Plan. En paralelo, comienzan a aparecer las primeras sentencias en su contra. A principios del 2009 el PTETLP recibe su primer fallo, el TSJC anula la norma 23 del Plan (Sentencia14/2009, 26/01/2009), conforme a la ya comentada denuncia formulada por la asociación empresarial Ashotel contra el Decreto 95/200718. Una circunstancia que suponía un importante revés en la intención de resolver el problema de las instalaciones turísticas sin licencia.

En marzo de 2013, el TSJC declaró nulo el Decreto 123/2008 (Sentencia 47/2013, 21/03/2013) y con ello parte del PTETLP y sus posibilidades de crecimiento turístico. Expectativas que recibirán un segundo revés cuando la Sala de lo Contencioso del Tribunal Supremo admitió el recurso y posteriormente anuló lo aprobado a través de Decreto 123/2008 (Recurso de casación 2524/2013, 18/05/2015), dando un golpe de gracia al PTETLP. Este juicio anulaba un total de 8.007 plazas, incluyendo infraestructuras decisivas en el modelo, como los campos de golf. Una decisión que además trajo demoledoras consecuencias sobre todos los instrumentos de ordenación que se habían adaptado al mismo.

El vicepresidente del Cabildo y consejero de Ordenación del Territorio, Carlos Cabrera, reconoció que la sentencia del Supremo era "un duro revés", propiciado por lo que calificó como "un mal plan para la isla de La Palma" (Diario de Avisos, 2/06/2015, p. 22) y contradictoriamente se apresuró a defender la vigencia de una parte del Plan. Idea reforzada desde el Gobierno regional, quien indicó que para una correcta lectura del fallo era preciso tener en cuenta que el PTETLP se había aprobado en varias fases, defendiendo la vigencia de lo contenido en los Decretos 95/2007 y 120/2010. Ahora bien, informes jurídicos

18 La norma 23 daba cobertura a plazas alojativas que, sin legalizarlas, les garantizaba una protección temporal hasta que los ayuntamientos las regulasen en su planeamiento general, vulnerando la Ley 7/1995, de Ordenación del Turismo de Canarias (BOC 48, 19/04/1995) y el Texto Refundido de las Leyes de Ordenación del Territorio de Canarias y Espacios Naturales de Canarias (BOC 157, 24/12/94). 
emanados del Cabildo Insular en relación con los efectos de la Sentencia del Tribunal Supremo, consideraron que estos Decretos se encontraban afectados de nulidad de pleno derecho. Los Servicios Jurídicos de la Dirección General de Ordenación del Territorio (Gobierno de Canarias) señalaban sin embargo lo contrario, creándose un contexto de total inseguridad e incertidumbre y en un escenario de vuelta a empezar.

\section{LA BÚSQUEDA DE UNA SOLUCIÓN A LA SENTENCIA ANULATORIA}

La Ley 14/2014, de 26 de diciembre, de armonización y simplificación en materia de protección del territorio y de los recursos naturales (BOC 2,5/01/2015), en su afán de facilitar el desarrollo del planeamiento territorial y urbanístico, habilitaba a los Planes Insulares la ordenación directa de los Sistemas Generales y Equipamientos estructurantes de trascendencia insular o supralocal, en los que cabían las infraestructuras vinculadas al ocio y los equipamientos complementarios al turismo. De esta forma podían quedar legitimados, a través de la aprobación de los correspondientes proyectos técnicos, buena parte de los presupuestos recogidos en el PTETLP. Con esta Ley, un año después de su anulación, se abre una puerta para resucitar el Plan y con ello volver a dinamizar las actuaciones turísticas anuladas.

El Plan Insular de La Palma (PIOLP) se encontraba en este momento en proceso de revisión, había superado la fase de aprobación, información y consulta del Avance y se disponía a continuar la tramitación del expediente con la aprobación de la propuesta de Memoria Ambiental y del documento de Aprobación Inicial. La Sentencia del Tribunal Supremo anulando el Decreto 123/2008 y la vía de la Ley 14/2014 supuso la interrupción y reformulación de este expediente. A finales del 2015, la Consejería de Política Territorial del Gobierno de Canarias y el Cabildo de La Palma acordaron definitivamente incorporar la ordenación turística de la Isla en la revisión del PIOLP, comenzando las reuniones entre representantes políticos, técnicos municipales y empresarios del sector para abordar la revisión, recabar ideas, así como distintas iniciativas en torno a la creación de nuevas infraestructuras de interés turístico ${ }^{19}$.

En paralelo se ensaya otra solución más determinante, la modificación del articulado de la Ley de las Islas Verdes del año 2002. Ya de facto existían distintas modificaciones parciales a esta Ley, como por ejemplo la realizada por la Leyes 14/2009 (BOC 2, 5/01/2010) y 14/2014 (BOC, 5/01/2015) de la que hemos dado cuenta, consideradas ambas como insuficientes para los objetivos de impulso de la oferta turística. La Consejería de Política Territorial, Sostenibilidad y Seguridad anunció entonces medidas previas para poder empezar a trabajar en la propuesta de modificación de la Ley 6/2002, en aras de conseguir los ansiados objetivos de convertir a la actividad turística en el instrumento de mayor capacidad de inducción al crecimiento económico y demográfico de las tres Islas Verdes.

Estas gestiones, instadas desde el Cabildo y los diputados regionales palmeros en forma de Proposición de Ley, fueron luego enmendadas en su totalidad por CC y PSOE, cristalizándose en la Ley 2/2016 de 27 de septiembre, para la modificación de la Ley

19 La actuación más relevante era el balneario de la Fuente Santa (Fuencaliente), pero además destacaban los centros de visitantes del Roque de los Muchachos (El Paso) y Cueva de las Palomas -Tubo Volcánico de Todoque (Los Llanos de Aridane), el Museo de la Sal en Los Cancajos (Breña Baja), el ascensor panorámico en Santa Cruz de La Palma, el Mirador del Universo (Tijarafe) y el proyecto del artista Ibarrola en Garafía, entre otros. 
6/2002, de 12 de junio, sobre medidas de ordenación territorial de la actividad turística en las islas de El Hierro, La Gomera y La Palma (BOC 194, 5/10/2016). Una norma que se aprueba con la intención de desbloquear la inversión turística insular, dando una respuesta ágil a la implantación turística de los sistemas generales, las dotaciones y los equipamientos estructurantes turísticos.

Las modificaciones contenidas en esta Ley eliminaron los matices que velaban por la sostenibilidad, el mantenimiento del sector primario y la conservación de los valores paisajísticos naturales y culturales de las zonas rurales de estas islas, dando de facto cobertura legal a la implantación del modelo de turismo convencional en el ámbito rural. En este sentido, la reforma refuerza al Plan Insular que se convierte en determinante en la decisiones sobre los equipamientos turísticos que presenten naturaleza estructurante y las instalaciones alojativas vinculadas a los mismos; se disminuyen las exigencias superficiales de las actuaciones en suelo rústico; se derogan las distancias mínimas entre actuaciones y se pone fin al carácter excepcional de las implantaciones turísticas en suelos rústicos de protección paisajística o cultural, así como la supresión de la obligación de poner y mantener en cultivo agrícola las parcelas anexas.

Ahora bien, con todo, la cuestión más destacable y polémica de esta reforma fueron los denominados Instrumentos de Planificación Singular Turística. Se trataba de instrumentos de ordenación territorial cuyas determinaciones prevalecían sobre el planeamiento insular y municipal, con un doble contenido: "ordenar y diseñar, para su inmediata ejecución", o bien directamente "ejecutar, los equipamientos insulares estructurantes turísticos". De iniciativa privada o pública, reconocidos como de interés general, carácter estratégico y urgente, podían aprobarse en ejecución del planeamiento insular o de forma autónoma, en este segundo caso, la planificación singular comprendía también la determinación y la localización de la infraestructura o actividad de que se tratara. Conforme a esta condición, se declararon de forma directa como de interés insular, es decir exonerados de esta declaración por parte del Cabildo, las actuaciones urbanísticas afectadas por la sentencia del Tribunal Supremo de mayo de 2015 que anuló el Decreto 123/2008 (Disposición Adicional 2a . 1. de la Ley 2/2016) ${ }^{20}$.

La aprobación de esta nueva ley aceleró la actividad de los históricos inversores: campos de golf de Breña Alta y Fuencaliente, Hotel de la Hacienda de Santa Lucía (Puntallana) y algunas pequeñas inversiones en suelo rústico (Barlovento). Ahora bien, la Isla carecía, a pesar de que el Cabildo intensificó las relaciones con promotores, sociedades y cadenas hoteleras, de nuevas iniciativas. Una situación justificada oficialmente por el largo tiempo en que había estado sometida a un escenario legal sumamente complejo y limitativo para la implantación de establecimientos turísticos en condiciones jurídicas favorables y seguras.

La Ley 2/2016 fue recurrida por el Grupo Parlamentario Podemos ante el Tribunal Constitucional, quien declaró (sentencia 42/2018) inconstitucional y nula la disposición

20 "Alguna/s de las actuaciones definidas y descritas como "actuaciones específicas previstas" (AEP), "actuaciones convencionales propuestas" (ACP) o "actuaciones estratégicas singulares" (SDO) en las fichas contenidas en el Anexo B de la Normativa del Plan Territorial Especial de Ordenación de la Actividad Turística de la isla de La Palma, publicadas en el Boletín Oficial de Canarias, de 10 de mayo de 2007”. (Ver tablas 3-5). 
adicional segunda y desestimó el recurso en todo lo demás (BOE 130, 29/05/2018)21 . La Unión Europea, a través de la Dirección General de Medio Ambiente y de Apoyo a los Estados Miembros, abrió una investigación de oficio y la Plataforma Canarias por un Territorio Sostenible presentó una denuncia en la Oficina de la Comisión Europea en Madrid. La Dirección General certificó (2017), que no incumplían la legislación europea en materia ambiental y, por lo tanto, no procedía hacer un seguimiento de las peticiones realizadas.

Estas resoluciones acabaron por consagrar el régimen específico para la actividad turística en las Islas Verdes, asumiéndose algunas particularidades relevantes en relación con otras islas del Archipiélago. Estas se concretan, de una parte, en la consideración del uso turístico en suelo rústico de forma ordinaria (régimen especial frente a un régimen ordinario restrictivo que se contempla para el resto de las islas).Y de otra, que la intervención vía instrumentos de ordenación singular turística pasara a ser una forma óptima que genera prontitud, especialmente en los procedimientos en circunstancias de urgencia.

\section{LA LEY DEL SUELO PARA CANARIAS (LEY 4/2017) Y SUS EFECTOS}

La promulgación de un nuevo texto legal que recogiera en una única ley todas las normas que regulaban la protección, ordenación y uso del suelo en Canarias, trajo, en tan solo cuatro meses de la aprobación de la Ley 2/2016,nuevos efectos en las Islas Verdes. Las modificaciones producidas con la Ley 4/2017, de 13 de julio, del Suelo y de los Espacios Naturales Protegidos de Canarias (BOC 138, 19/07/2017), fueron sobre todo de ajuste a lo que era la norma básica regional, insistiendo una vez más en el objetivo de avanzar de forma rápida en el desarrollo turístico.

Un aspecto de la nueva legislación, especialmente celebrado por su implicación en La Palma, fue la desaparición de la COTMAC y su sustitución, para los instrumentos insulares, por un órgano designado por el Cabildo. La Palma fue pionera en la constitución de este órgano. La denominada "Cotmac Palmera", fue constituida a finales de 2017 con una provisionalidad total y con una discutible capacidad, para, en palabras de su presidente insular: "permitir que sea el Cabildo Insular, en el marco de la isla, el que evalúe proyectos, programas y planes, y de esa manera ser más ágiles a la hora de tramitarlos y resolverlos por estar más cercanos al territorio". De esta forma se conseguían dos viejas aspiraciones insulares: la "independencia" en la toma de decisiones y la agilidad en los trámites.

Las trabas administrativas se solventaban, pero la inversión turística privada seguía sin apostar por la Isla. La discutida "Cotmac Palmera" en estos últimos años solo ha aprobado villas turísticas y alojamientos en el medio rural. Los grandes proyectos, a pesar de los constantes rumores de reactivación turística en la isla, especialmente en la vertiente suroeste, siguen sin llegar. La ausencia de un empresariado dispuesto a invertir ha supuesto su sustitución por la Administración, en un intento de suscitar con el ejemplo a la inversión privada. Siguiendo las palabras de la Consejera de Política Territorial: "no podemos esperar que un hotelero o un empresario de ocio nos toque en la puerta; en La Palma necesitamos un impulso público" (Diario de Avisos, 27/12/2017, p. 42).Y así, el Cabildo de La Palma

21 El recurso, en síntesis, indicaba su oposición a la implantación de establecimientos turísticos, de sistemas generales y de equipamientos turísticos en suelo rústico y se oponía a la declaración de interés insular de determinadas actuaciones que estaban previstas en el PTETLP. 
apoyado en el Fondo de Desarrollo de Canarias (FDCAN) ${ }^{22}$, promueve en la actualidad acciones encaminadas a la creación y mejora de las infraestructuras turísticas que incrementen la dotación de la Isla y que a su vez permitan ampliar el espectro de turistas potenciales, incorporando tipologías que todavía no estaban presentes, como por ejemplo el turismo de congresos (Parque Cultural y Centro de Convenciones Islas Canarias, Los Llanos de Aridane) o el turismo de Salud (Balneario de la Fuente Santa, Fuencaliente), entre otros ${ }^{23}$.

\section{CONCLUSIONES}

La desigual implantación de la actividad turística derivada de las condiciones geográficas, sociales y económicas insulares ha motivado un desarrollo económico diferenciado y desigual entre las islas de El Hierro, La Gomera y La Palma (Islas Verdes) y las restantes islas de Canarias (Islas Turísticas). La Palma, entre estas tres islas, por dimensión territorial, poblacional y económica, es la que presenta una posición más avanzada, aunque no exenta de problemas.

La Palma ha estado históricamente alejada del modelo turístico litoral o "de masas" característico del Archipiélago. No será hasta finales de los años 80, con la ampliación del aeropuerto, cuando tímidamente despegue el interés por aumentar su oferta alojativa, aunque siempre bajo la consideración de actividad complementaria a la agricultura de exportación. Ahora bien, las dificultades en las comunicaciones, el hecho de que las zonas costeras (las de mayor rentabilidad turística) fueran ocupadas por la rentable actividad platanera y una atomizada y conservadora pequeña propiedad, frenaron estas iniciales expectativas, quedando los pequeños núcleos litorales de Los Cancajos y Puerto Naos como excepcionalidades de un modelo económico que preferentemente seguía apostando por el monocultivo platanero y los ingresos públicos, compartido con una modesta actividad turística rural en alojamientos dispersos y preexistentes.

A mediados de la década de los 90, este tradicional modelo económico comienza a mostrar, vinculado a las incertidumbres respecto a las ayudas al sector primario, relativos indicios de cambio. Es en este momento cuando se apuesta institucionalmente por materializar los proyectos urbanísticos especulativos recogidos desde la mitad de los 80 en sus respectivos planes y que no se habían materializado ante el carácter predominante de la economía platanera, una estrategia que choca frontalmente con una política regional de contención al crecimiento, convirtiéndose este aspecto en la contradicción central recurrente que ha caracterizado casi dos décadas plagadas de leyes específicas, reformas de éstas, planes y senten-

22 El Fondo de Desarrollo de Canarias (FDCAN), tiene como función promover la realización de acciones que contribuyan a la cohesión económica y social territorial, al desarrollo económico de Canarias y a la creación de empleo en las islas.http://www.gobiernodecanarias.org/presidencia/temas/Fondo-de-Desarrollo-de-CanariasFDCAN/

23 Una vez terminado el presente artículo se produjo una nueva modificación a la Ley Turística de las Islas Verdes, Ley 14/2019 (BOC 90, 13/05/2019), una norma aprobada sin consenso que establece especialidades puntuales de tipologías turísticas y que destaca especialmente el protagonismo del planeamiento insular en cuanto a la zonificación y a la determinación de las condiciones de implantación en suelo rústico y los instrumentos de planificación singular turística, abriendo el camino una vez más al desarrollo turístico en la Isla. 
cias, en un intento infructuoso por incorporar a la Isla a un marco general de terciarización inmobiliario-turística, al que había llegado no sólo tarde sino en el momento más inoportuno.

La ley 6/2001 y especialmente la 6/2002 y su innovador modelo de desarrollo turístico en suelo rústico recogido en el Plan Territorial Especial Turístico (PTETLP), sirvió para canalizar las aspiraciones de llegar en el año 2020 a 20.500 camas, todo ello en un contexto de ansiedad por desarrollar un conjunto de actuaciones turísticas aisladas de gran magnitud, impacto y desconocidas en la Isla, que servirían como punta de lanza de su crecimiento socioeconómico, enfrentando positivamente el escaso dinamismo poblacional de las últimas décadas, así como el permanente interrogante en torno al futuro de su economía de base agroexportadora.

Una cascada de reparos formales, solicitud de subsanación de errores y recelos administrativos, supusieron la aprobación del PTETLP en fases. A esto se le añadió un cúmulo de sentencias en contra que culminaron con la anulación del Plan. Todo este conjunto de inconvenientes administrativos generó daños colaterales. El más relevante fue la fuga de no pocos inversores externos ante la inseguridad manifiesta de la apuesta, que no fue compensada con la inversión local. En una isla caracterizada por una cultura emprendedora por debajo de la media regional, pequeños agricultores y comerciantes isleños, con nula experiencia en el sector, se mostraron reacios e incapaces de acometer las inversiones diseñadas.

La reacción a ambos problemas fue, de una parte, buscar soluciones administrativas para desatascar la parálisis acontecida tras el fallo anulatorio del Alto Tribunal: utilización de todos los resquicios legales posibles en leyes generales como la 14/2014 y la 4/2017; "reutilización" de instrumentos existentes como el PIOLP, aprovechando los contenidos de nuevas leyes; así como modificar leyes específicas para la Isla (Ley 2/2016). Por otra parte, en el terreno económico la estrategia se concreta en la asunción desde presupuestos públicos de los costes de algunas infraestructuras emblemáticas, con la intención de que éstas sirvan de tirón a otras privadas. Un proceso de momento en marcha pero que aún no ha mostrado los resultados esperados.

Para terminar, el ejemplo de La Palma es un magnífico modelo del papel que tiene el sistema jurídico en el desarrollo económico y las contradicciones que este puede producir en el contexto regional. En este periodo estudiado, la actividad turística palmera está y ha estado supeditada a leyes e instrumentos globales de carácter regional, que han proyectado y proyectan una determinada forma de concebir el desarrollo económico insular. Y he ahí la razón fundamental del problema, los límites regionales han chocado con la intensión expansiva insular y local. Las leyes planteadas desde el poder regional en pro de una estrategia global para toda Canarias, no fueron consensuadas y excluían a una parte del Archipiélago, chocando con un modelo de heterogéneas economías insulares, cuando no locales, en las que La Palma, por dinamismo, ha sido punta de lanza y ejemplo. 


\section{BIBLIOGRAFÍA}

CABILDO INSULAR DE LA PALMA (2001): La Palma, Planificación Estratégica. Santa Cruz de La Palma, Excmo. Cabildo Insular de La Palma.

CABILDO INSULAR DE LA PALMA (2007): Plan Territorial Especial de Ordenación de la actividad turística de la isla de La Palma. Director equipo redactor: Félix Rodríguez de la Cruz.

DARANAS CARBALLO, R. (1999): «Turismo y planeamiento en la isla de La Palma», Cuadernos de Ordenación del Territorio, $\mathrm{n}^{\circ}$ 6, pp. 23-28.

FERNÁNDEZ HERNÁNDEZ, C. (2010): Estudio de las preferencias del turista rural en la isla de La Palma. Tesis Doctoral dirigida por F.M. Díaz Pérez, Universidad de La Laguna. Inédita.

GONZÁLEZ, A.; HERNÁNDEZ, J.A. y PARREÑO, J.M. (2016): «Los usos turísticos en la Reserva de la Biosfera de la isla de La Palma (Canarias)», Boletín de la Asociación de Geógrafos Españoles n $\mathrm{n}^{\circ}$ 70, pp. 239-257.

GOBIERNO DE CANARIAS (s/f). Borrador de Compromiso por el Desarrollo Sostenible de Canarias. Disponible en http://www.datosdelanzarote.com/Uploads/doc/Desarrollo-sostenible-de-Canarias-20160418100637315D3-5-Completo.pdf[Consultado el 26/05/2017].

HERNÁNDEZ GÓMEZ, A. (1994): «Plan Insular de La Palma». En L.M. GARCÍA HERRERA, y J. SÁNCHEZ GARCÍA. (Coord.): Los Planes Insulares de Ordenación en Canarias. Reflexiones metodológicas. Santa Cruz de Tenerife, Gobierno de Canarias - Universidad de La Laguna, pp.61-84.

HERNÁNDEZ GÓMEZ, A. (2000): «El Plan Insular de Ordenación de La Palma». En GARCÍA RODRÍGUEZ, J.L.: Protección y uso del territorio en La Palma. El debate sobre el modelo insular de desarrollo. Santa Cruz de Tenerife, Excmo. Cabildo Insular de La Palma y Caja General de Ahorros de Canarias, pp. 95-128.

HERNÁNDEZ LUIS, J.A. (2000): «El desarrollo turístico de La Palma». En J.L. GARCÍA RODRÍGUEZ.: Protección y uso del territorio en La Palma. El debate sobre el modelo insular de desarrollo. Santa Cruz de Tenerife, Excmo. Cabildo Insular de La Palma y Caja General de Ahorros de Canarias, pp. 321-355

HERNÁNDEZ LUIS, J.A. (2009): «El malogrado despertar turístico de La Palma de los años sesenta y setenta», Turismo. Revista de Estudios de Turismo de Canarias y la Macaronesia, $\mathrm{n}^{\circ} 1$, pp. 117-142.

HERNÁNDEZ LUIS, J.A.; GONZÁLEZ MORALES, A. y PARREÑO CASTELLANO, J.M. (2016): «Los orígenes del turismo en la isla de La Palma: la década de los sesenta del siglo XX», Anales de Geografía de la Universidad Complutense vol. 36 (1), pp. 71-90.

HERNÁNDEZ RODRÍGUEZ, G.F. (2006): «Turismo sostenible en La Palma, un territorio Reserva de la Biosfera», Ambienta. Revista del Ministerio de Medio Ambiente, $\mathrm{n}^{\circ} 61$, pp.56-63.

LÓPEZ RAMÍREZ, M.C. (2007): «Un modelo de turismo distinto al adoptado en las islas orientales: modelo de gestión de la actividad turística basado en criterios de sosteni- 
bilidad y medioambiente para la isla de La Palma», Revista de Estudios Generales de La Palma, $\mathrm{n}^{\mathrm{o}}$ 3, pp. 543-592.

MORALES HERNÁNDEZ, A.M. (2017): La oferta alojativa de turismo rural en la isla de La Palma: análisis desde una perspectiva de género. Tesis Doctoral dirigida por F.M. Díaz Pérez, C. Fernández Hernández y C.G. García González. Universidad de La Laguna. Inédita.

OLMOS, M. (1998): «Isla de La Palma (Canarias), mucho más que turismo», Actualidad Leader. Revista de Desarrollo Rural, $\mathrm{n}^{\circ} 2$, pp. 26-27.

SIMANCAS CRUZ, M.R. (2015): La moratoria turística de Canarias. La reconversión de un destino maduro desde la Ordenación del Territorio. La Laguna, Servicio de Publicaciones, Universidad de La Laguna.

SIMANCAS CRUZ, M.R. (2019): «Especulación urbanística y burbuja inmobiliaria en espacios litorales: factores explicativos del Tercer Boom turístico de Canarias», Cuadernos de Turismo, $\mathrm{n}^{\circ}$ 43, pp. 471-497.

VILLAR ROJAS, F. J. (2016): «El marco normativo de definición del modelo turístico canario». En M. SIMANCAS CRUZ y E. PARRA LÓPEZ.: ¿Existe un modelo turístico canario? Santa Cruz de Tenerife, Promotur, pp.32-51.

\section{FUENTES DOCUMENTALES (WEB)}

BOC. Boletín Oficial de Canarias. Santa Cruz de Tenerife/Las Palmas de Gran Canaria. http://www.gobiernodecanarias.org/boc/

BOE. Boletín Oficial del Estado. Madrid. https://www.boe.es/

Canarias 7. Las Palmas de Gran Canaria. https://www.canarias7.es/

COTMAC. Comisión de Ordenación del Territorio de Canarias. Santa Cruz de Tenerife/ Las Palmas de Gran Canaria.http://www.gobiernodecanarias.org/cptss/politica-territorial/temas/evaluacion-ambiental/cotmac/

DIARIO DE AVISOS. Santa Cruz de Tenerife. https://diariodeavisos.elespanol.com/

EL DÍA. Santa Cruz de Tenerife. https://www.eldia.es/

LA OPINIÓN. Santa Cruz de Tenerife. https://www.laopinion.es/

LA PROVINCIA. Las Palmas de Gran Canaria. https://www.laprovincia.es/

PROMOTUR. Turismo de Canarias. Gobierno de Canarias. https://turismodeislascanarias. com/es/

TC. Tribunal Constitucional de España. Madrid. https://www.tribunalconstitucional.es/es/ Paginas/default.aspx

TSJC. Tribunal Superior de Justicia de Canarias. Santa Cruz de Tenerife.http://www.poderjudicial.es/cgpj/es/Poder-Judicial/Tribunales-Superiores-de-Justicia/TSJ-Canarias/

T.S. Tribunal Supremo. Madrid. http://www.poderjudicial.es/cgpj/es/Poder-Judicial/Tribunal-Supremo/ 